\title{
DE-FC-26-05NT42416: Heavy-Duty Stoichiometric Compression Ignition Engine with Improved Fuel Economy over Alternative Technologies for Meeting 2010 On-Highway Emission - Final Report
}

Report Period: 8/10/2005 to 12/31/2007

Kirby J. Baumgard (Primary Contact), Richard E. Winsor

John Deere Power Systems

P.O. Box 8000

Waterloo, IA 50704

Phone: (319) 292-8995

E-mail: BaumgardKirbyJ@JohnDeere.com

DOE Technology Development Manager: John Fairbanks

Phone: (202) 586-8066

E-mail: John.Fairbanks@ee.doe.gov

Subcontractors:

Ricardo Incorporated, Van Buren Twp, MI

Purdue University, West Lafayette, IN

Sturman Industries, Woodland Park, CO

Disclaimer: This report was prepared as an account of work sponsored by an agency of the United States Government. Neither the United States Government nor any agency thereof, nor any of their employees, makes any warranty, express or implied, or assumes any legal liability or responsibility for the accuracy, completeness, or usefulness of any information, apparatus, product, or process disclosed, or represents that its use would not infringe privately owned rights. Reference herein to any specific commercial product, process, or service by trade name, trademark, manufacturer, or otherwise does not necessarily constitute or imply its endorsement, recommendation, or favoring by the United States Government or any agency thereof. The views and opinions of authors expressed herein do not necessarily state or reflect those of the United States Government or any agency thereof.

\section{Phase I Objectives}

- Apply the stoichiometric compression ignition (SCI) concept to a 9.0 liter diesel engine.

- Obtain engine-out NOx and PM exhaust emissions so that the engine can meet 2010 on-highway emission standards by applying a three-way catalyst for NOx control and a particulate filter for PM control.

- Simulate an optimize the engine and air system to approach 50\% thermal efficiency using variable valve actuation and electric turbo compounding.

\section{Accomplishments}

- Demonstrated that an advanced diesel engine can be operated at stoichiometric conditions with reasonable particulate and NOx emissions at full power and peak torque conditions.

- Calculated that the SCI engine will operate at $42 \%$ brake thermal efficiency without advanced hardware, turbocompounding, or waste heat recovery. 
- Determined that EGR is not necessary for this advanced concept engine, and this greatly simplifies the concept.

\section{Future Directions}

Since the SCI concept has shown reasonable engine-out NOx and PM emissions with good fuel economy potential, the next critical issue is whether the three-way catalyst will provide the necessary NOx control. At the same time, further refinement of this engine concept is being conducted to improve the fuel efficiency. The near-term future work in rough chronological order is:

- Procure three-way catalyst and write software to control A/F ratio to properly operate the catalyst.

- $\quad$ Determine if the three-way catalyst NOx efficiency will be acceptable (>95\%).

- Improve combustion system based on CFD results and experiments to increase combustion efficiency and reduce smoke.

- Optimize the air system for the lower flows inherent with stoichiometric operation.

- Order Variable Valve Actuation system for engine control at lighter loads.

- Determine heat rejection and evaluate thermal loading on in-cylinder components.

\section{Introduction}

Various concepts have been proposed to meet the 2010 on-highway emission standards with improved fuel efficiency. The Stoichiometric Compression Ignition (SCI) engine concept combines advantages of a diesel engine with simple, reliable exhaust aftertreatment to provide low emissions with superior fuel economy.

In this concept, a diesel engine operates at stoichiometric at all times so that a three-way catalyst can be used to control NOx to very low levels without adding additional fuel or other chemicals. Because the engine-out NOx emissions are reduced substantially by the catalyst, the combustion process in the cylinder can be improved to increase fuel efficiency. The reduced air flow and increased exhaust temperature due to stoichiometric combustion allow further engine changes to improve system fuel efficiency.

\section{Approach}

For this research a John Deere heavy-duty engine is being used. The initial task was to demonstrate a diesel engine running at stoichiometric to assess the viability of the concept. After conducting some air system simulation and computational fluid dynamic calculations of the combustion process, the engine was operated at full power and peak torque. Some optimization of the combustion and air system was conducted, and more work is planned for the next phase of development. Also, the three-way catalyst, diesel particulate filter, and a variable valve actuation (VVA) system will be procured for the next phase.

Later phases of this project involve demonstrating the 2010 on-highway emission standards using VVA and exhaust aftertreatment, and then adding an electric turbocompounding system. Further optimization would be conducted to obtain the goal of $50 \%$ overall engine thermal efficiency. Finally, the complete system would be integrated 
into a prototype vehicle and the performance and fuel economy of the advanced SCI engine will be evaluated.

\section{Phase I Results}

A John Deere six-cylinder 9.0 liter engine rated at $248 \mathrm{~kW}$ at $2100 \mathrm{rpm}$ was used for testing. The air system and injection system were modified during development. In this first year of the program three series of engine tests were conducted.

In the first series several injector nozzles were evaluated at loads up to 50\%, since the air system would not provide EGR at higher loads and therefore turbine inlet temperatures became excessive. With the preferred nozzles, smoke and particulate levels were acceptable, but the air system needed to be modified to provide the required EGR at higher loads.

For the second set of engine tests, the John Deere 9L engine was plumbed to use both high pressure loop EGR and low pressure loop EGR. However, it was found that there was an engine control stability problem when using the high-pressure-loop. Simulation work confirmed that this control instability was inherent with high-pressure-loop EGR. Using low-pressure-loop EGR, full load rated speed and peak torque conditions were obtained at stoichiometric air/fuel ratio, although considerable intake, exhaust, and charge cooler restriction had to be added to reduce the air flow to the proper level.

The smoke emissions were high using the production injection system at $200 \mathrm{MPa}$ injection pressure, so six different nozzle configurations were evaluated at peak torque and rated power conditions, and some trends were observed. The smoke responded to normal combustion system variables like spray angle, hole number, injection duration, injection timing, etc., but remained high. As expected, smoke was very sensitive to equivalence ratio, so exhaust emissions were used to determine this value. This is commonly referred to as the carbon balance method (CBM). NOx emissions were low, and therefore the 2010 on-highway standard should be easily achievable with a three-way catalyst. The engine BSFC was higher than expected because of the additional restrictions necessary to reduce the air flow. During the testing, cylinder pressure data was collected and provided to Ricardo and Purdue to incorporate into their modeling work.

With the six hole nozzles, test points were obtained near stoichiometric with approximately $750 \mathrm{C}$ turbine inlet temperature (obtained by varying EGR percentage). This turbine inlet temperature limit was necessitated by the VTG turbocharger. Analysis of the data showed that smoke was quite sensitive to EGR percentage and that the EGR levels and exhaust temperatures were slightly different among the data points. Therefore, linear regressions were generated for both engine operating conditions (peak torque and rated power).

Regression results predicted smoke from the best nozzle at stoichiometric with $750 \mathrm{C}$ exhaust temperature to be 5.6 Bosch at rated and 5.2 Bosch at peak torque. The conclusion from the analysis was that we needed further nozzle changes and reduced 
EGR (increased exhaust temperature). The strong effect of EGR on smoke suggested that eliminating EGR would greatly reduce the smoke, and results from other engine development activities without EGR have given smoke levels of 1 to 2 Bosch at stoichiometric, which should be acceptable for the DPF. Therefore, means to allow engine operation with reduced EGR were sought. It was decided that using a watercooled exhaust manifold would give reasonable turbine inlet temperature without EGR. Although this was expected to give acceptable smoke levels, NOx emissions became a concern. However, since the NOx removal efficiency of a three-way catalyst in diesel exhaust is unknown, the maximum acceptable NOx level is unknown.

The CFD model of combustion in the 9L engine was updated using the cylinder pressure data at rated power and peak torque from this second series of engine tests. The simulation predicted some of the PM changes with nozzle changes, but there were some discrepancies. A brief examination of changing the piston bowl shape did not indicate a significant improvement was likely.

Meanwhile, further refinement of the engine simulation with low-pressure-loop EGR indicated that $200 \mathrm{~g} / \mathrm{kWh}$ BSFC (42\% brake thermal efficiency) was achievable, although additional backpressure has to be added after the DPF in order to drive the clean EGR to the compressor inlet. Attention was shifted to the water-cooled exhaust manifold without EGR, and the heat release was changed to represent combustion without EGR. The WAVE simulation predicted that without EGR 40 to $42 \%$ brake thermal efficiency was achievable even with exhaust aftertreatment. Also, this engine simulation work showed that variable turbine geometry (VTG) with about twice the flow of the production turbocharger was needed to avoid excessive boost.

Unfortunately, no VTG turbocharger was available with suitable turbine and compressor sizes. This is because unusually high exhaust energy is available with the SCI engine while only moderate boost levels and flows are needed from the compressor. Therefore, a larger fixed turbocharger with a pneumatically-operated wastegate on the turbine housing was used for the third series of engine tests. Although the air system was not optimal, the goal was to achieve proper in-cylinder conditions in order to determine the NOx and PM emissions. Then measured engine performance data can be adjusted using simulation to represent an air system designed for the SCI engine concept.

It was originally intended that the third series of engine tests would use the experimental Sturman S1.3 system with elevated injection pressures. This is an intensified injection system that uses fuel at up to $120 \mathrm{MPa}$ to drive a piston which pressurizes the injected fuel up to $300 \mathrm{MPa}$. Sturman Industries adapted the system to the Deere 9L engine with an ECU to drive the injectors, while the Deere ECU controlled the VTG and EGR system. The engine with the injection system installed was tested for operability and shipped to Deere. However, injector and nozzle failures with the Sturman S1.3 system at about $240 \mathrm{MPa}$ on the test stand at low hours have been a concern. The nozzle failures are apparently due to pressure spikes generated by the intensifier system, since the same nozzles have much longer life when used at the same pressure with the production common rail system. Sturman is exploring nozzle design alternatives. Because of the 
lack of robustness of the Sturman injection system, the third series of engine tests used experimental Denso G3 injectors, which are very robust at pressures above 220MPa. To provide sufficient high-pressure fuel to operate these injectors, an available experimental setup using a gearbox to drive two Denso rail pumps was used initially. Unfortunately, the gearbox failed early in the testing, so a single pump was used for most of this test series, which limited the available rail pressure, especially at lower engine speeds.

The third series of engine tests was run without any EGR to reduce the smoke and particulates. To reduce the turbine inlet temperature to an acceptable level (750 to 800 C), a water-cooled exhaust manifold was installed. This manifold is used for marine versions of the 9L engine. Estimates indicated that the coolant heat rejection from the water-cooled exhaust manifold would be similar to the heat rejection from cooling the EGR in the previous setup. However, a future turbocharger design that will tolerate higher turbine inlet temperatures would reduce the need for exhaust cooling and improve the engine system efficiency.

In addition to the water-cooled exhaust manifold, a large wastegated turbocharger was installed, since the available VTG turbocharger had been unable to reduce the boost to the required level. Even with the wastegate wide open and the water-cooled exhaust manifold, it was found that the boost was excessive, so additional intake, charge cooler, and exhaust restrictions were added. A wide-range oxygen sensor was used to quickly set the operating conditions to stoichiometric, and with this sensor, we were able to consistently collect data very near to stoichiometric.

While maintaining stoichiometric F/A ratio, rail pressure and injection timing were varied at rated power and peak torque conditions. The test results are compared to previous data with EGR in Figures 1 and 2, where the results without EGR have high NOx and low smoke. It can be seen that the smoke goal was met without EGR, although NOx was higher than desired. However, the NOx goal was based on an assumed efficiency for the three-catalyst. If the NOx removal efficiency is sufficiently high, the engine-out NOx level of 5 to $6 \mathrm{~g} / \mathrm{kWh}$ would be acceptable. Figure 3 shows engine-out emission results at FLRS and peak torque are within our revised goals. It should be noted that these emission results will be further improved with an optimized air system because the engine will generate more power while using the same amount of fuel and air. The results on the SCI engine without EGR are summarized by the rated power and peak torque operating points tabulated in Figure 4. The results show reasonable NOx at 5.4 $\mathrm{g} / \mathrm{kWh}$ and reasonable PM at $0.13 \mathrm{~g} / \mathrm{kWh}$. The measured BSFC is shown for reference, but it is high because of extra air system restrictions and an inefficient turbocharger with an open wastegate. WAVE simulation by Ricardo are being used to optimize the air system and predict the fuel economy with reasonable components and restrictions.

The recent tests of the SCI engine concept without EGR gave good combustion with reasonable NOx and smoke. Therefore, it does not appear that extremely high injection pressures will be necessary to have acceptable smoke and particulate emissions, although additional injector nozzles have been ordered and CFD calculations are being made to further improve combustion. Consequently, the problems with the Sturman injection 
system will not delay the program. Also, the elimination of EGR has greatly simplified the engine concept, although the addition of a water-cooled exhaust manifold increases heat rejection.

Now that reasonable smoke and particulate emissions have been obtained without EGR, the next major issue is control of NOx emissions. A three-way catalyst has been ordered and $\mathrm{A} / \mathrm{F}$ ratio controls are being developed to operate the catalyst at stoichiometric in order to determine the efficiency of NOx removal. About 95\% efficiency on NOx removal is needed, which is well within the capability of a three-way catalyst system operating on gasoline engine exhaust, but the efficiency on diesel exhaust may be lower.

Predictions of the engine efficiency were made using the Ricardo WAVE model with heat release calculated from the engine running without EGR and reasonable air system components. The engine model was rebaselined using the most recent data operating at stoichiometric conditions, then the air system of the model was modified to utilize a properly sized turbocharger with reasonable efficiencies and to include the additional air required for the particulate filter. The predicted brake thermal efficiency at rated power and peak torque were 37.1 and $38.5 \%$, respectively.

Although these efficiencies are not very attractive, it is very early in the engine development process. A number of improvements are planned to increase the fuel efficiency. First, more rapid combustion is important and CFD calculations indicate that nozzle changes will improve the mixing and thereby result in more rapid heat release nearer to TDC. Second, preliminary WAVE runs with more optimum intake closure and exhaust opening timing have shown potential for efficiency improvement. This is because the less dense cylinder charge due to lower boost levels requires less time to enter and exit the cylinder. Air system restrictions can be reduced further based on the reduced air and exhaust flows and reduced charge cooling requirement of the SCI engine, and turbocharger efficiency may be improved. Also, the bypass air flow of $10 \%$ of the engine air flow might be reduced if the DPF can be continuously regenerated with less oxygen.

\section{Conclusions}

Although it is early in the development of the stoichiometric diesel engine concept, there are a number of significant findings:

- An advanced diesel engine can be operated at stoichiometric with reasonable particulate and NOx emissions.

- The low boost requirements and absence of EGR make this SCI engine concept attractive.

- The reduced engine air flow and reduced exhaust flow at high temperature provide advantages for further system optimization to improve fuel economy.

- Stoichiometric engine operation may allow higher specific output, i.e. smaller engine displacement, than other advanced diesel engine concepts providing the same power.

- A three-way catalyst efficiency of about $95 \%$ is needed to meet the NOx standards. 
- The SCI engine requires in-cylinder thermal barrier coatings and/or improved cooling of the cylinder head to obtain acceptable cylinder head metal temperatures.

- Brake thermal efficiency of 50\% with electric turbocompounding and optimization should be obtainable.

\section{Acronyms}

$\begin{array}{ll}\text { A/F } & \text { Air to Fuel ratio } \\ \text { BSFC } & \text { Brake Specific Fuel Consumption } \\ \text { DPF } & \text { Diesel Particulate Filter } \\ \text { ECU } & \text { Engine Control Unit } \\ \text { EGR } & \text { Exhaust Gas Recirculation } \\ \text { FLRS } & \text { Full Load Rated Speed engine condition } \\ \text { g/kWh } & \text { grams/kilowatt-hour } \\ \text { NO } & \text { Nitrogen monoxide } \\ \text { NO2 } & \text { Nitrogen dioxide } \\ \text { NOx } & \text { Oxides of Nitrogen } \\ \text { PM } & \text { Particulate Matter } \\ \text { SCI } & \text { Stoichiometric Compression Ignition } \\ \text { VTG } & \text { Variable Turbine Geometry } \\ \text { VVA } & \text { Variable Valve Actuation }\end{array}$

Figures 


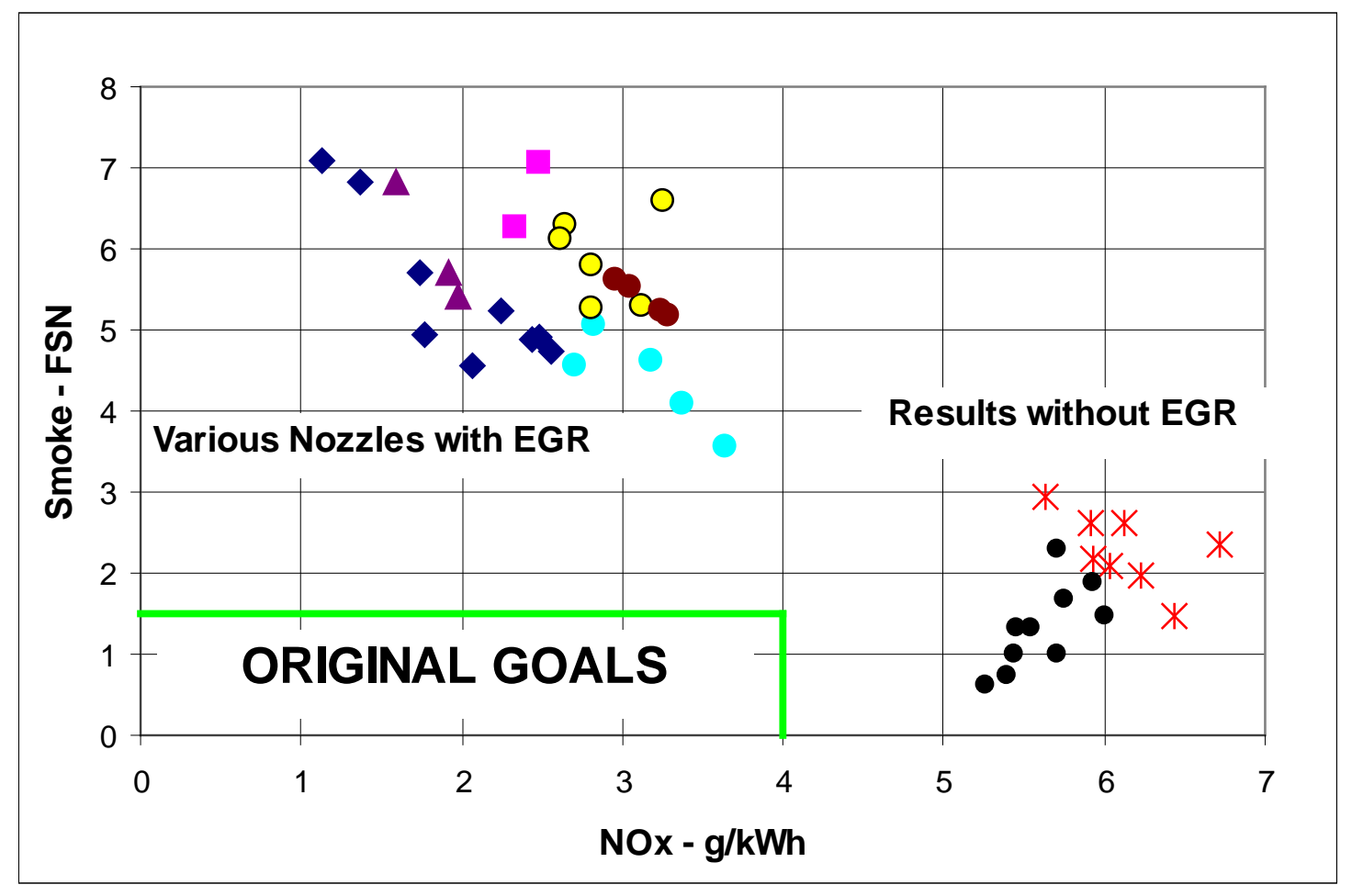

Figure 1. Comparison of Results from Second Test with EGR and Third Test without EGR at FLRS

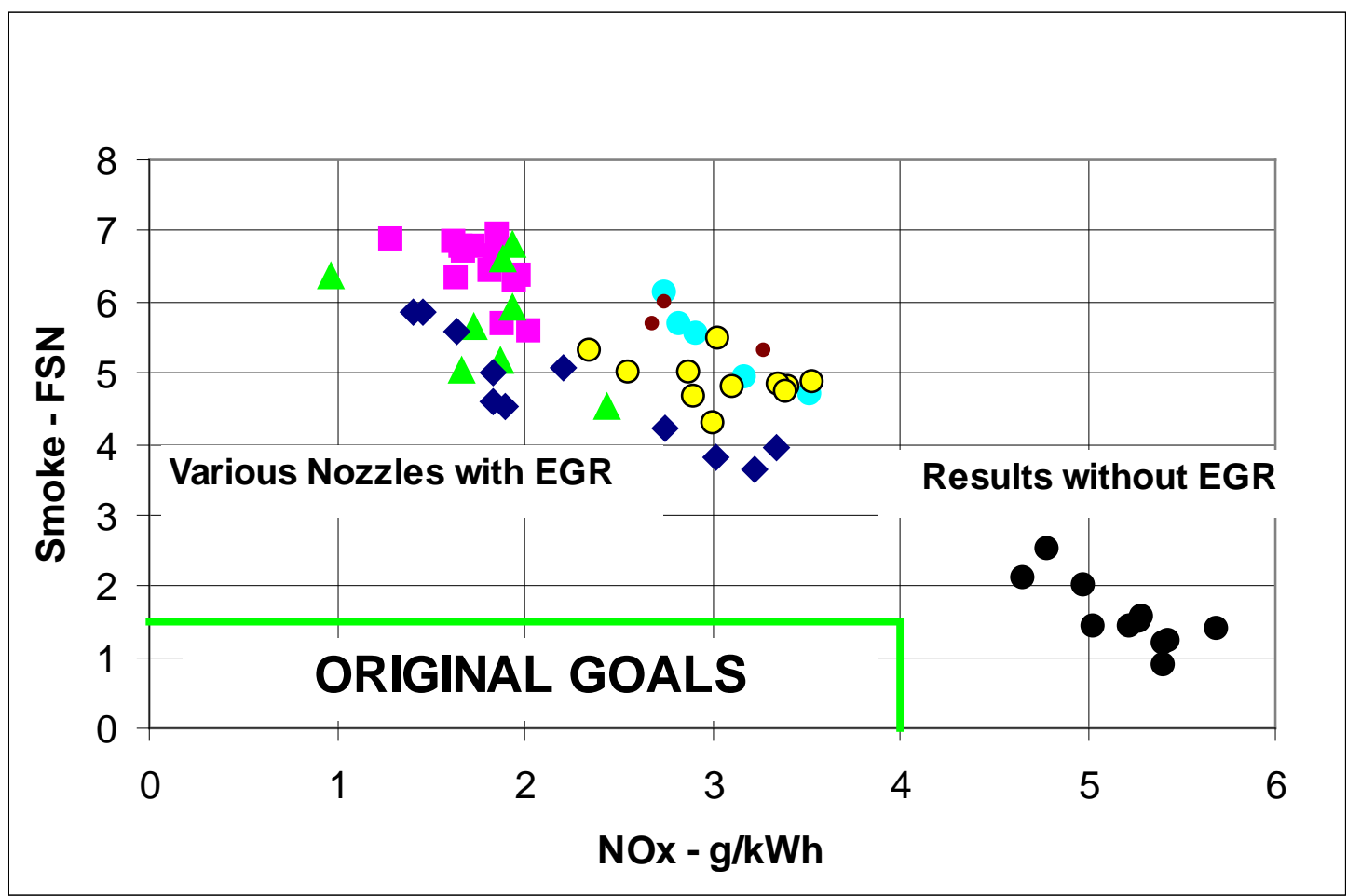

Figure 2. Comparison of Results from Second Test with EGR and Third Test without EGR at Peak Torque 


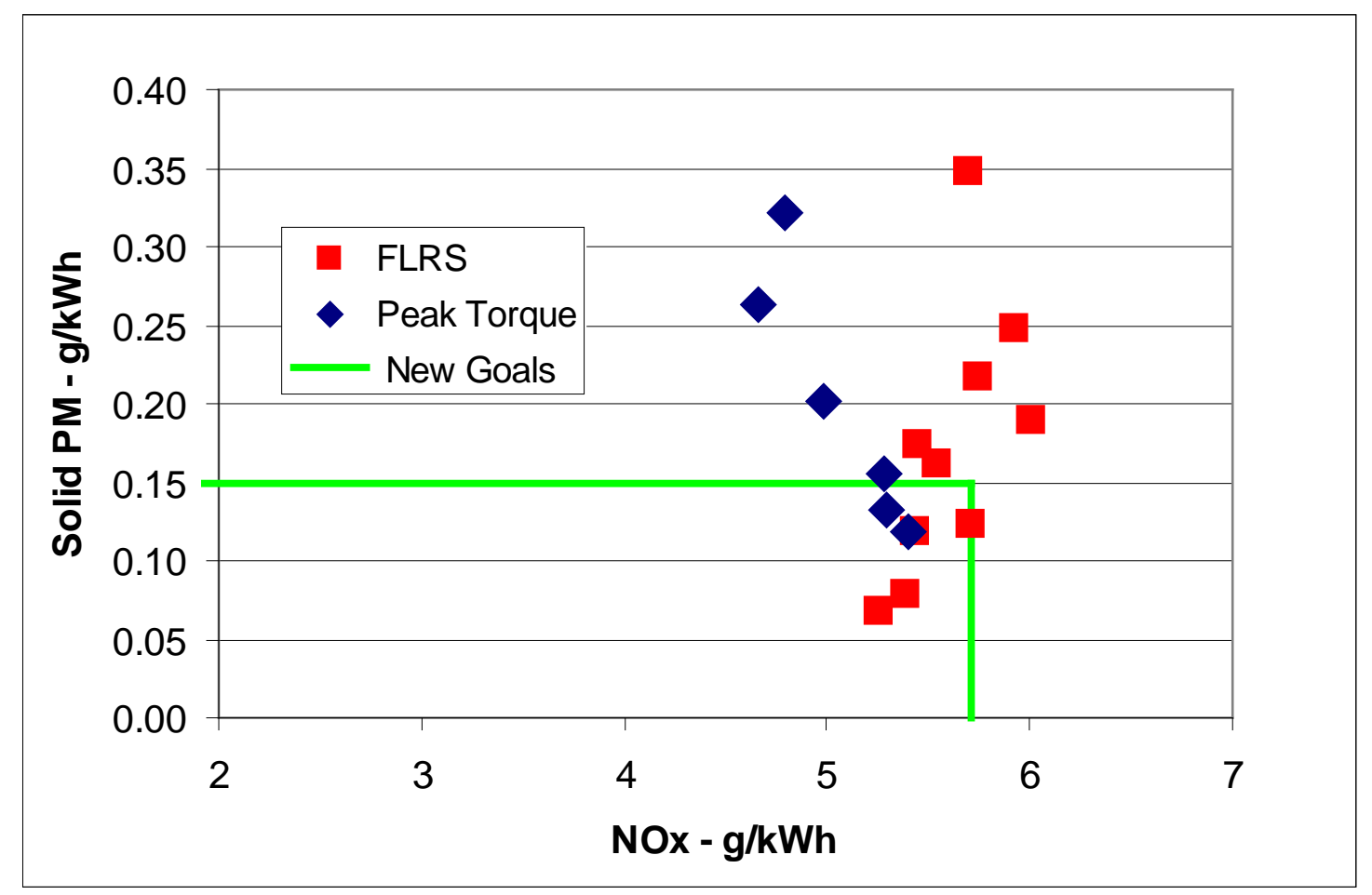

Figure 3. Engine-Out Emission Results without EGR

\begin{tabular}{|cccc|} 
Speed & $\mathrm{rpm}$ & 2100 & 1575 \\
Torque & $\mathrm{N}-\mathrm{m}$ & 1124 & 1522 \\
Smoke & $\mathrm{FSN}$ & 1.0 & 1.2 \\
Turbine Inlet & $\mathrm{C}$ & 798 & 767 \\
O2 & $\%$ & 0.5 & 0.5 \\
HC & $\mathrm{g} / \mathrm{kWh}$ & 0.00 & 0.01 \\
CO & $\mathrm{g} / \mathrm{kWh}$ & 16.1 & 26.9 \\
NOx & $\mathrm{g} / \mathrm{kWh}$ & 5.4 & 5.4 \\
PM & $\mathrm{g} / \mathrm{kWh}$ & 0.13 & 0.12 \\
BSFC & $\mathrm{g} / \mathrm{kWh}$ & 234.0 & 219.2 \\
Inlet Restr. & $\mathrm{kPa}$ & 7.0 & 3.2 \\
Intercooler & & & \\
Restr. & $\mathrm{kPa}$ & 17.3 & 12.2 \\
Exhaust Restr. & $\mathrm{kPa}$ & 16.7 & 9.4 \\
\hline
\end{tabular}

Figure 4. Tabulated Summary of Operation at FLRS and Peak Torque without EGR 